Article

\title{
Effect of Biochar on Soil Temperature under High Soil Surface Temperature in Coal Mined Arid and Semiarid Regions
}

\author{
Jibing Xiong ${ }^{1, *}$, Runhua Yu ${ }^{1}$, Ejazul Islam ${ }^{2}$, Fuhai Zhu ${ }^{1}$, Jianfeng Zha ${ }^{1, *}$ and \\ Muhammad Irfan Sohail ${ }^{3}$ (D) \\ 1 Jiangsu Key Laboratory of Resources and Environment information Engineering, China University of \\ Mining and Technology, Xuzhou 221116, China; yrh17718150868@163.com (R.Y.); zhufuhai@runrise.cc (F.Z.) \\ 2 Soil \& Environmental Biotechnology Division, National Institute for Biotechnology and Genetic \\ Engineering (NIBGE), Faisalabad 38000, Pakistan; ejazulislam75@yahoo.com \\ 3 Institute of Soil and Environmental Sciences, Faculty of Agriculture, University of Agriculture, \\ Faisalabad 38040, Pakistan; Irfansohail9@gmail.com \\ * Correspondence: xiongjib108@163.com (J.X.); Zhajianfeng@cumt.edu.cn (J.Z.)
}

Received: 13 September 2020; Accepted: 5 October 2020; Published: 7 October 2020

\begin{abstract}
High soil surface temperature and loosened soil are major limiting factors of plant productivity in arid and semi-arid coal mining areas of China. Moreover, the extensive and illegitimate burning of crop residues is causing environmental pollution; whereas, these residues could be converted to biochar to benefit soil quality. In this study, the effect of wheat straw biochar (WSB) at rates of $0 \%$ (control, CK), 1\% (low, LB), 2\% (medium, MB) and 4\% (high, HB) on soil temperature at different depths $(5,10,15$, and $20 \mathrm{~cm}$ ) and moisture levels (10 and 20\%) was investigated under high soil surface temperature of $50{ }^{\circ} \mathrm{C}$ and air humidity of $40 \%$. Our data suggested that soil bulk density was inversely, and soil moisture was directly corelated with soil thermal parameters. Moreover, the increasing rate of WSB addition linearly decreased the soil thermal properties. The maximum decrease in soil bulk density at both moisture levels $(10 \%$ and $20 \%)$ was measured in HB treatment compared to respective CKs. The highest decrease in soil thermal conductivity (59.8\% and 24.7\%) was found under HB treatment in comparison to respective controls (CK10\% and CK20\% moisture). The soil volumetric heat capacity was also strongly corelated with soil moisture content $(\mathrm{r}=0.91)$. The WSB treatments displayed differential responses to soil temperature. Under $10 \%$ soil moisture, temperature of $\mathrm{LB}, \mathrm{MB}$ and $\mathrm{HB}$ treatments was higher as compared to $\mathrm{CK}$ at 5-20 cm depth, and $\mathrm{MB}$ treated soil had the smallest increase in temperature. At the $15-\mathrm{cm}$ depth, the MB treatment decreased the temperature by $0.93{ }^{\circ} \mathrm{C}$ as compared to the $\mathrm{CK} 20 \%$. Therefore, the effect of WSB on soil temperature was influenced by soil moisture content, soil depth and WSB application rates. It suggested that $\mathrm{MB}$ treatment could be a useful farming practice for mitigating soil temperature fluctuation.
\end{abstract}

Keywords: coal mining; arid and semiarid regions; high soil temperature; soil productivity; biochar

\section{Introduction}

Soil temperature is an important variable influencing a range of physical, chemical, and biological processes occurring in soil [1]. Soil temperature is not only a critical factor for plant growth, but it also influences the soil respiration and regulates the transport of water, salts, and mineral nutrients. Conversely, it is also significantly influenced by soil bulk density, soil organic matter (SOM), soil texture, moisture, and air temperature [2,3]. Investigating the impact of mining activities on soil quality is an exigent research field. Half of the coal reserves of China are in the arid-semiarid areas [4]. Rapid 
exploitation of coal resources has left various regions with a legacy of destroyed soil [5]. Large masses of soil have been loosened and exposed to air and solar radiations due to surface cracking provoked by underground mining [6]. The loosened soil is more easily influenced by high air temperature compared with the undisturbed soil. The maximum surface temperature often reaches $50-60{ }^{\circ} \mathrm{C}$ in arid and semi-arid soils [7,8]. High soil temperature has accelerated the SOM decomposition [9], and plant productivity is constantly declining [10,11]. Therefore, it is imperative to investigate the impact of temperature in arid and semi-arid coal mining areas.

Biochar (BC) is a stable carbon-rich material obtained when feedstock is heated in a closed container with meager or no available oxygen [12,13]. Diversified C-based feedstocks can be used, and resultant product characteristics differ not only on the bases of feedstock, but it also changes due to variations in pyrolysis conditions (temperature, speed, duration, etc.) [14]. BC is quite porous in structure and is characterized by a low bulk density and high surface area. Compared to mineral soil bulk density $\left(1.16\right.$ to $2.00 \mathrm{~g} \mathrm{~cm}^{-3}$ ), the bulk density of $\mathrm{BC}$ ranges from 0.08 to $1.7 \mathrm{~g} \mathrm{~cm}^{-3}$. The BC soil amendment is not only a winning strategy for C-sequestration or soil remediation, but it promotes numerous soil health properties including soil moisture retention capacity, manipulation of bulk density, regularization of soil temperature, etc. [15] Previously, the effect of BC amendment on soil temperature has been explained by the combined actions of changes in soil thermal conductivity, reflectance, and variation in albedo [16].

Field burning of wheat straw/residues is a common agronomic practice for easy soil tillage purposes, which accelerates the carbon dioxide $\left(\mathrm{CO}_{2}\right)$ emission and particulate matter, ultimately harming human and environmental health [17]. Numerous environment- and agriculture-related agencies in China have enforced legal restrictions on the field burning of crop residues [18] and crop residues are required to return to the field after crushing, but it may increase incidences of soil-crop diseases [19]. Therefore, such feedstocks offer a sublime opportunity to transform residues into irreplaceable resource for soil health and sustainability. Moreover, the soil moisture links the energy cycles and temperature. The link from soil moisture to temperature occurs when limited soil moisture availability restricts the amount of energy used for evaporation [20]. The variation of the soil-water environment may cause different soil temperature conditions [16]. As temperature and soil moistures are directly linked, therefore, we consider the soil moisture a significant variable affecting the soil temperature [21].

Contemporary, researchers are focusing on elucidating the impact of $\mathrm{BC}$ on soil thermal properties. Zhao et al. [22] found that $B C$ addition significantly decreased soil thermal diffusivity in the North China Plain. Liu et al. [23] reported that BC addition reduced the difference between day and night soil temperatures by $0.66-1.39{ }^{\circ} \mathrm{C}$ in paddy soils. However, the effect of $\mathrm{BC}$ on soil temperature under high soil surface temperature and low air moisture has not been explained well. Only few recent reports $[16,24,25]$ have highlighted the BC-soil temperature relationship in temperate/tropical croplands but not in arid or semi-arid climates. Therefore, this laboratory scale study investigated the effect of wheat straw biochar (WSB) at different application rates on soil temperature with different soil depths and soil moisture under high surface temperature $\left(50^{\circ} \mathrm{C}\right)$ and low air moisture $(40 \%)$.

\section{Materials and Methods}

\subsection{Soil Used in Study}

Soil was collected from Da-Liu-ta coal mining areas in Yulin City, Shanxi Province, China. The soil was air dried and passed through a 2-mm mesh sieve prior to any use. The soil type belonged to Chestnut soil and texture was silt soil (USDA classification) with $0.11 \%$ sand, $96.86 \%$ silt, and $2.93 \%$ clay. This composition was analyzed by laser diffraction technique using Rise-2006 Particle Size Analyzer (Runzhi instruments, China). The chemical parameters analyzed were: soil $\mathrm{pH}$ analyzed through 1:5 soil/water ratio using $\mathrm{pH}$ meter (PHS-3B, China) was 8.94; the electrical conductivity (EC) measured 
through 1:5 soil/water ratio using EC meter (HM AP-2, South Korea) was $82 \mu \mathrm{S} \mathrm{cm}{ }^{-1}$; and total organic carbon was $2.7 \mathrm{~g} \mathrm{~kg}^{-1}$ (Elementar, Vario TOC Cube, Germany).

\subsection{Wheat Straw Biochar Preparation}

The wheat straw for WSB preparation was collected from a single farmer's wheat field near Xuzhou City, Jiangsu Province, China. Prior to WSB production, the wheat straw was chopped into suitable sizes and then oven-dried for $24 \mathrm{~h}$ at $65^{\circ} \mathrm{C}$. The dried wheat straw was transferred to a controllable programmed electric muffle furnace. The temperature for each cycle was monitored. The feedstock was pyrolyzed at temperature $300{ }^{\circ} \mathrm{C}$ at the rate of $4{ }^{\circ} \mathrm{C} \mathrm{min}-1$ in the presence of nitrogen at a flow rate of $2 \mathrm{~L} \mathrm{~min}^{-1}$. After attaining the temperature $300^{\circ} \mathrm{C}$, the feedstock was allowed to stay for $60 \mathrm{~min}$. When the furnace cooled down to room temperature, the biochar was collected and was sieved through a 2-mm mesh sieve to get the uniform particle size distribution.

\section{Characterization of WSB}

The WSB was characterized for its physical properties using the "Hot Disk TPS-2500" thermal constants analyzer. The moisture contents were $1.4 \%$, bulk density was $180 \mathrm{kgm}^{-3}$, thermal conductivity was $0.06 \mathrm{Wm}^{-1} \mathrm{~K}^{-1}$, volumetric heat capacity was $0.21 \mathrm{MJm}^{-3} \mathrm{~K}^{-1}$, and thermal diffusivity was measured as $2.8510^{-7} \mathrm{~m}^{2} \mathrm{~s}^{-1}$.

\subsection{Chamber Experiment}

The soil was amended with WSB at the rate of $0 \%$ (control, CK), 1\% (low biochar addition, LB), $2 \%$ (medium biochar addition, $\mathrm{MB}$ ), and $4 \%$ (high biochar addition, $\mathrm{HB}$ ) with soil moisture being adjusted to $10 \%$ and $20 \%(\mathrm{w} / \mathrm{w})$, respectively, for each group by adding deionized water. The WSB was thoroughly mixed in soil prior to filling the plastic containers/pipes. Each treatment had three replicates. The amended soil samples were filled in polypropylene random (PPR) insulation pipes (16 cm diameter) which conduced heat from top to the bottom of the pipe, simulating field conditions. The experiment was performed in an artificial climate chamber. Air temperature and humidity inside the artificial climate chamber was controlled at $50^{\circ} \mathrm{C}$ and $40 \%$, respectively. Initial soil temperature was $30^{\circ} \mathrm{C}$. Thermometers $\left(0-50^{\circ} \mathrm{C}\right)$ were inserted in each of the PVC tubes at depths of 5, 10, 15, and $20 \mathrm{~cm}$

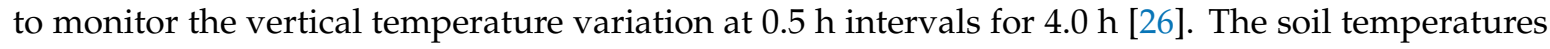
were recorded at every 30-minute interval.

\subsection{Statistical Design, Data Processing, and Analysis}

This experiment was conducted according to a randomly complete block design set up and the experiment was repeated three times. Treatment differences were analyzed at $5 \%$ probability level by Duncan multi-range tests one-way ANOVA using IBM-SPSS Statistics for Windows, Version18.0. Armonk, NY: IBM Corp. The correlation and regression analyses were further conducted by SPSS 18.0 to offer more insight into moisture content on soil bulk density, thermal conductivity, and volumetric heat capacity with WSB addition. The representation and graphical fits of experimental data were obtained with Origin 8.0. by OriginLab corporation Massachusetts USA.

\section{Results and Discussion}

\subsection{Effect of WSB Application on Different Soil Heat Parameters and Their Relationships}

The effect of WSB application rates with respect to different moisture levels was evaluated for soil heat parameters (bulk density, thermal conductivity, volumetric heat capacity, thermal diffusivity, and the statistical data processing showed significant variations $(p<0.05)$ which has been displayed in (Table 1). The bulk density was found to be inversely related to WSB rates in both soils having different moisture contents. The maximum decrease in soil bulk density at both moisture levels $(10 \%$ and $20 \%)$ was measured where WSB was applied at a higher dose ( $4 \%$ HB treatment) when compared with CK 
at the respective soil moisture content. The soil bulk density was decreased by $34.6 \%, 24.7 \%$ in $\mathrm{HB}$ at $10 \%$ and $20 \%$ soil moisture content, respectively. The Pearson correlation analysis (Table 2) signifies that the soil bulk density was greatly influenced by the WSB application rates and moisture content. The soil bulk density was related strongly to moisture content $(r=0.81, p<0.01, n=24$; Table 2) at WSB addition. The distinct reduction in soil bulk density at same moisture content can be attributed to the low density and high porosity of WSB [27]. Yan et al. [25] also found that $9.6 \%$ decrease occurred at a high rate $\left(60 \mathrm{tha}^{-1}\right)$ of the biochar application rate. Similarly, the highest decrease in bulk density in our case is also attributed to low density and higher porosity which favored the stable aggregation of soil particles, but some authors have warned that too many higher application rates of biochar could affect the water storage capacity of the soil $[25,28]$.

Table 1. Thermal parameters of soil with different moisture content under different application rates of wheat straw biochar.

\begin{tabular}{|c|c|c|c|c|c|}
\hline & Treatments & $\begin{array}{l}\text { Bulk Density } \\
\quad\left(\mathrm{kgm}^{-3}\right)\end{array}$ & $\begin{array}{c}\text { Thermal } \\
\text { Conductivity } \\
\left(\mathrm{Wm}^{-1} \mathrm{~K}^{-1}\right)\end{array}$ & $\begin{array}{c}\text { Volumetric Heat } \\
\text { Capacity } \\
\left(\mathrm{MJm}^{-3} \mathrm{~K}^{-1}\right)\end{array}$ & $\begin{array}{c}\text { Thermal } \\
\text { Diffusivity } \\
\left(10^{-7} \mathrm{~m}^{2} \mathrm{~s}^{-1}\right)\end{array}$ \\
\hline \multirow{4}{*}{$\begin{array}{l}\text { Moisture } \\
\text { content } \\
(10 \%)\end{array}$} & CK & $1790 \mathrm{a}$ & $1.17 \mathrm{a}$ & $1.94 \mathrm{a}$ & $6.04 \mathrm{a}$ \\
\hline & LB & $1380 \mathrm{~b}$ & $0.87 \mathrm{~b}$ & $1.61 \mathrm{~b}$ & $5.41 \mathrm{~b}$ \\
\hline & MB & $1300 \mathrm{c}$ & $0.68 c$ & $1.52 \mathrm{~b}$ & $4.46 \mathrm{c}$ \\
\hline & HB & $1170 \mathrm{~d}$ & $0.47 \mathrm{~d}$ & $1.35 \mathrm{c}$ & $2.97 \mathrm{~d}$ \\
\hline \multirow{4}{*}{$\begin{array}{l}\text { Moisture } \\
\text { content } \\
(20 \%)\end{array}$} & CK & $2270 \mathrm{a}$ & $2.01 \mathrm{a}$ & $2.80 \mathrm{a}$ & $7.18 \mathrm{a}$ \\
\hline & LB & $2220 \mathrm{~b}$ & $2.08 \mathrm{a}$ & $2.92 \mathrm{a}$ & $7.13 \mathrm{~b}$ \\
\hline & MB & $1930 \mathrm{c}$ & $1.67 \mathrm{~b}$ & $2.56 \mathrm{~b}$ & $6.53 c$ \\
\hline & $\mathrm{HB}$ & $1710 \mathrm{~d}$ & $0.88 c$ & $2.27 \mathrm{c}$ & $3.87 \mathrm{~d}$ \\
\hline
\end{tabular}

Table 2. Correlation matrix for soil bulk density, moisture content, thermal conductivity, volumetric heat capacity.

\begin{tabular}{ccc}
\hline Parameter & Soil Bulk Density & Moisture Content \\
\hline soil bulk density & $0.96^{* *}$ & $0.81^{* *}$ \\
thermal conductivity & $0.75^{* *}$ \\
volumetric heat capacity & $0.91^{* *}$ \\
\hline Statistically significant difference at $p<0.05,{ }^{* *}$ Statistically significant difference at $p<0.01$.
\end{tabular}

The soil thermal conductivity was linearly decreased with increasing the rate of WSB addition at $10 \%$ or $20 \%$ soil moisture content $(p<0.05$; Table 1$)$. When compared with the $\mathrm{CK}$ at $10 \%$ soil moisture content, the decrease in soil thermal conductivity by LB, MB, and HB treatments was $25.6 \%, 41.8 \%$, and $59.8 \%$, respectively. On the contrary, when the thermal conductivity was at $20 \%$ soil moisture content, the LB resulted in a 3.5\% increase. Meanwhile, MB and HB decreased the thermal conductivity by $16.9 \%$ and $56.2 \%$, respectively. Similarly, our data suggest that the soil thermal conductivity was affected not only by the soil bulk density but also by the soil moisture as thermal conductivity was positively correlated in strong association with soil moisture $(\mathrm{r}=0.75, p<0.01, n=24$; Table 2). On the other hand, the soil thermal conductivity was positively correlated with the soil bulk density $(\mathrm{r}=0.96, p$ $<0.01, n=24$; Table 2). Therefore, the addition of WSB induced the changes in soil bulk density and soil moisture content. Usowicz et al. [29] indicated that the rate of thermal conductivity increased as soil moisture content increased, but the thermal conductivity increase was smaller in soil with lower rather than higher bulk density. In addition, the lower inherent thermal conductivity of WSB $\left(0.06 \mathrm{Wm}^{-1} \mathrm{~K}^{-1}\right)$ may have contributed to the decline in the soil thermal conductivity. Although the soil temperature conduction is greatly influenced by environmental factors, the carbon (C) contents in soil can have a greater influence on conductivity. Our results confirm the findings of previous reports suggesting that the changes in the thermal conductivity of soil carbon are affected by the surface structure of WSB [24]. Thermal conductivity is a vital indicator to soil heat flow, and it is significantly affected by 
soil texture, structure, moisture, and management practices, and it increases with bulk density and moisture content, similar to our findings (Table 1) [27].

Thermal diffusivity is another significant soil thermal propriety and it is a ratio of thermal conductivity and heat capacity. Our results show that HB treatment of WSB was the most efficient and $\mathrm{HB}$ was able to decrease the thermal diffusivity by $50.8 \%$ and $46 \%$ at $10 \%$ and $20 \%$ moisture content, compared to control (CK10\%) and (CK 20\%) treatments. The soil thermal diffusivity was also significantly decreased with increasing biochar addition rates at both $10 \%$ and $20 \%$ soil moisture content $(p<0.05$; Table 1$)$. When compared with the control at $10 \%$ soil moisture content, the soil thermal diffusivity in the LB treatment was decreased by $10.4 \%$. However, when compared with CK at $20 \%$ soil moisture content, the decrease in soil thermal diffusivity in LB was minimal $(0.7 \%)$. Compared with control (CK) treatments of $10 \%$ and $20 \%$ soil moisture content, the MB treatment led to a $26.1 \%$ and $9.0 \%$ decrease in thermal diffusivity. The thermal diffusivity reflects the soil temperature and heat flux [28]. Significant decreases in the soil thermal diffusivity due to biochar suggested less soil temperature variation after biochar amendment, as reported by Zhang et al. [27]. The soil volumetric heat capacity was also significantly decreased with increasing WSB treatments at both $10 \%$ and $20 \%$ soil moisture content $(\mathrm{P}<0.05$; Table 1$)$. When compared with control $(\mathrm{CK} 10 \%)$ and CK $20 \%$ treatments, the maximum decrease (30\% and $18.9 \%)$ was observed under HB treatments, respectively. The soil volumetric heat capacity contents in the LB treatment was decreased by $17.2 \%$ and $4.2 \%$ compared to control (CK 10\%) and CK $20 \%$ treatments, while a decrease in volumetric heat capacity by MB treatment was $21.4 \%$ and $8.7 \%$, respectively. The soil volumetric heat capacity is mainly influenced by the soil bulk density and moisture content as it has been presented in previous reports [22,23]. The results of our study showed that the soil volumetric heat capacity was also correlated strongly to moisture content $(\mathrm{r}=0.91, p<0.01, n=24$; Table 2$)$ at WSB addition. Soil is a highly complex system consisting of solid-liquid-gas. In arid or semi-arid ecosystems, soil surface covered with organic matter is an inevitable factor for the restoration of soil physical properties [30]. Additionally, the restoration of microbiota in such degraded arid land is pivotal for soil sustainability i.e., Karimi et al [31] demonstrated that the application of corn biochar produced at $200{ }^{\circ} \mathrm{C}$ is more efficient than biochar produced at a higher pyrolytic temperature for increasing soil DOC and CEC, soil micronutrient availability, soil moisture, microbial biomass, and catalase and dehydrogenase activity in arid calcareous soils. Among all the soil components, the soil moisture has the highest specific heat capacity. Even a minor change in soil moisture content may result in a significant change in the soil heat capacity. In addition to soil moisture contents, the BC amendments also contain a significant inherent specific heat capacity, which is higher than the average specific heat capacity of organic matter and minerals. Given the same moisture content and volume, the heat capacity of biochar is 1.61 times higher than that of soil. Therefore, the addition of BC amendments like WSB impose a significant impact on the soil system. Notably, the specific heat capacity of the soil solid phase was increased significantly by WSB addition in our study and the same has been suggested in previous reports [22]. The addition of $\mathrm{BC}$ leads to a change in soil water content and soil bulk density which further yields variations in soil thermal conductivity and other heat parameters [27].

\subsection{Effect of WSB Application on Soil Temperature Variations at Different Soil Moisture Contents}

\subsubsection{Effect of WSB Application on Soil Temperature Variations at 10\% Soil Moisture Contents}

The results presented in (Figure 1) demonstrate that WSB amendments applied at different rates led to fluctuations in soil temperature. Relative to the control (CK10\%), the WSB treatments displayed differential responses to soil temperature. Generally, with increasing WSB rates, the soil temperature increased at $10 \%$ moisture contents, compared to CK $10 \%$, at all four depths $(5,10,15$, and $20 \mathrm{~cm})$ as shown in Figure 2 (A, B, C, and D), respectively. The HB treatment proved to be the most influential treatment which increased the soil temperature across the $0-20 \mathrm{~cm}$ soil profile. At $5-\mathrm{cm}$ soil depth and $10 \%$ soil moisture, there was a swift increase in soil temperatures for the treatments during initial 1st 
hour of incubation and a later the rise in temperature was gradual until the $3 \mathrm{rd} h$ after addition and finally a stable curve displayed at the 4.0th $\mathrm{h}$ (Figure 1A). For $5 \mathrm{~cm}$ depth, results showed that soil temperature of LB treatment was significantly greater than all other treatments. Initially at 0.5 th $h$, the LB treatment had a rapid increase in temperature, which was $0.81,1.80$, and $1.78{ }^{\circ} \mathrm{C}$ greater than $\mathrm{MB}$, $\mathrm{HB}$, and $\mathrm{CK} 10 \%$ treatments, respectively (Figure $1 \mathrm{~A}$ ). Later, at $1.0 \mathrm{~h}$, the LB treatment was decreased by 0.73 and $0.28{ }^{\circ} \mathrm{C}$ lower than the $\mathrm{MB}$ and $\mathrm{HB}$ treatment. At $10-\mathrm{cm}$ soil depth, the soil temperature of all the treatments continued to increase compared to the $5-\mathrm{cm}$ soil depth. Soil temperature of LB treatment was increased by $0.79,1.52$, and $1.98^{\circ} \mathrm{C}$ in $\mathrm{MB}, \mathrm{HB}$, and $\mathrm{CK}$ treatments at $0.5 \mathrm{~h}$, respectively (Figure $1 \mathrm{~B}$ ); and $0.11,0.02$, and $0.76^{\circ} \mathrm{C}$ in $\mathrm{MB}, \mathrm{HB}$, and $\mathrm{CK}$ treatments at $2.0 \mathrm{~h}$ (Figure $1 \mathrm{~B}$ ). Soil temperatures of LB, $\mathrm{MB}$, and $\mathrm{HB}$ treatment were $0.65,0.47$, and $0.76{ }^{\circ} \mathrm{C}$ greater than $\mathrm{CK}$ treatment at $4.0 \mathrm{~h}$ at $10-\mathrm{cm}$ soil depth. During the 0.5 th $\mathrm{h}$ measurement at $15 \mathrm{~cm}$ soil depth, the $\mathrm{LB}, \mathrm{MB}$, and HB treatments decreased the soil temperature by $0.18,0.29$, and $1.28{ }^{\circ} \mathrm{C}$, respectively compared to the $\mathrm{CK} 10 \%$. Contrary to the 0.5 th $\mathrm{h}$ measurement, the $\mathrm{LB}, \mathrm{MB}$, and $\mathrm{HB}$ showed the opposite trend by increasing the soil temperature by $0.40,0.42$, and $0.22{ }^{\circ} \mathrm{C}$, respectively at the 2.0th $\mathrm{h}$. Finally, the 4 th $\mathrm{h}$ measurements showed that the $\mathrm{LB}, \mathrm{MB}$, and $\mathrm{HB}$ treatments increased the soil temperature by $0.48,0.50$, and $0.31^{\circ} \mathrm{C}$, respectively, compared to $\mathrm{CK} 10 \%$, showing a $37.53{ }^{\circ} \mathrm{C}$ temperature (Figure 1C). Amazingly, at a lower soil profile (15-20 cm depth), the soil temperatures irrespective to treatments were lower than in the upper soil profile $(0-10 \mathrm{~cm})$, but the soil temperature of WSB treatments was still higher than the CK treatment with a maximum difference of $0.16^{\circ} \mathrm{C}$ recorded at the $3 \mathrm{rd} \mathrm{h}$ (Figure 1D). Overall, the soil temperatures of $\mathrm{LB}, \mathrm{MB}$, and $\mathrm{HB}$ treatments were higher compared to the $\mathrm{CK}$ treatment, which was similar to the findings of Usowicz et al. [29], who found in Poland that wood biochar application increased the amplitude of daily soil temperature in a fallow soil. This may be due to $\mathrm{BC}$ addition decreasing the volumetric thermal capacity, while the dark of color of biochar can reduce the albedo of the soil surface [29,32].
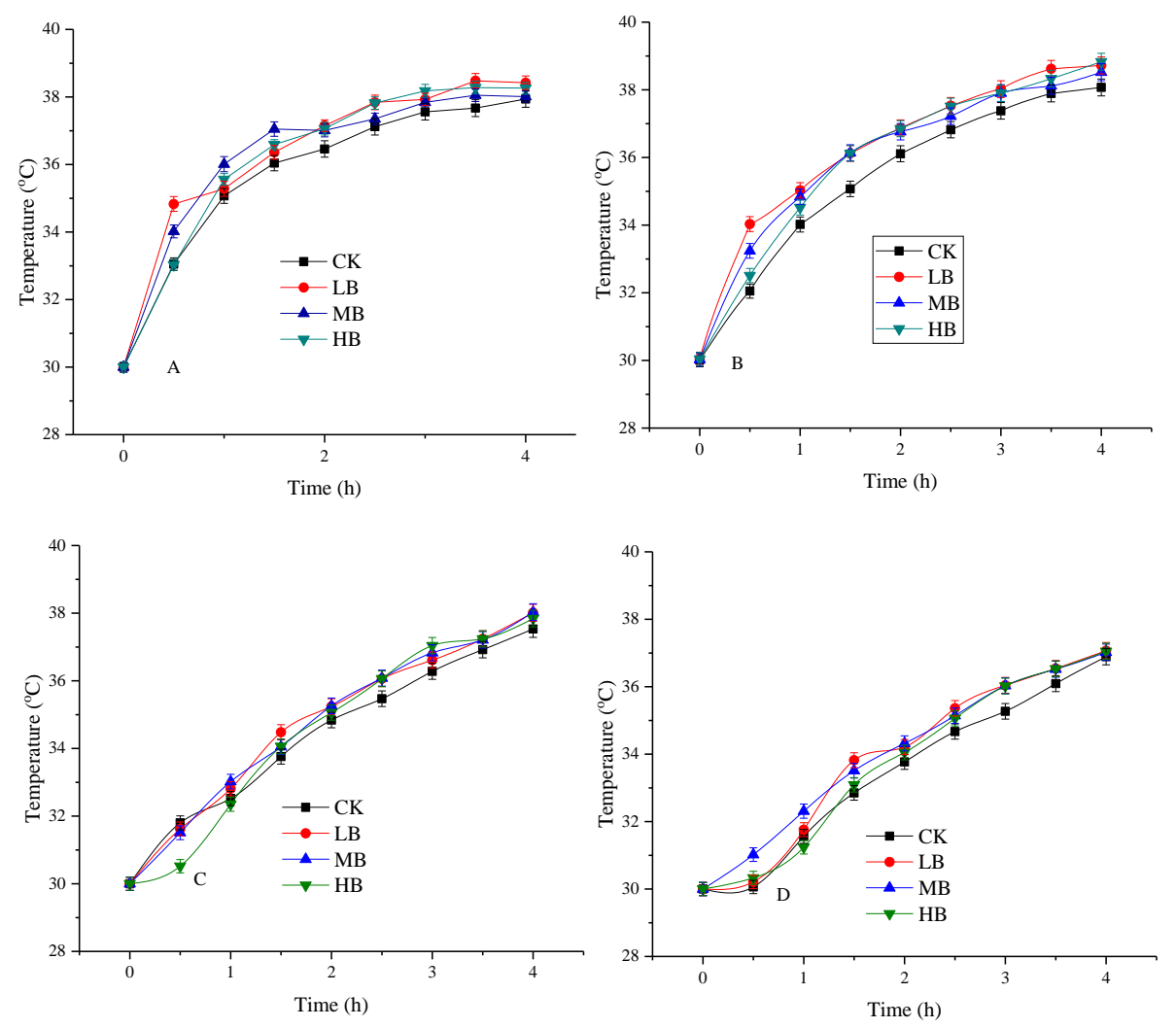

Figure 1. Effect of different wheat straw biochar application rates on soil temperature at different soil depths: A-5 cm, B- $10 \mathrm{~cm}, \mathrm{C}-15 \mathrm{~cm}$, and D- $20 \mathrm{~cm}$ (with initial soil moisture $10 \%$, air temperature $50{ }^{\circ} \mathrm{C}$ and air humidity $40 \%$ ). CK, control; LB, low biochar; $\mathrm{MB}$, medium biochar; $\mathrm{HB}$, high biochar. 

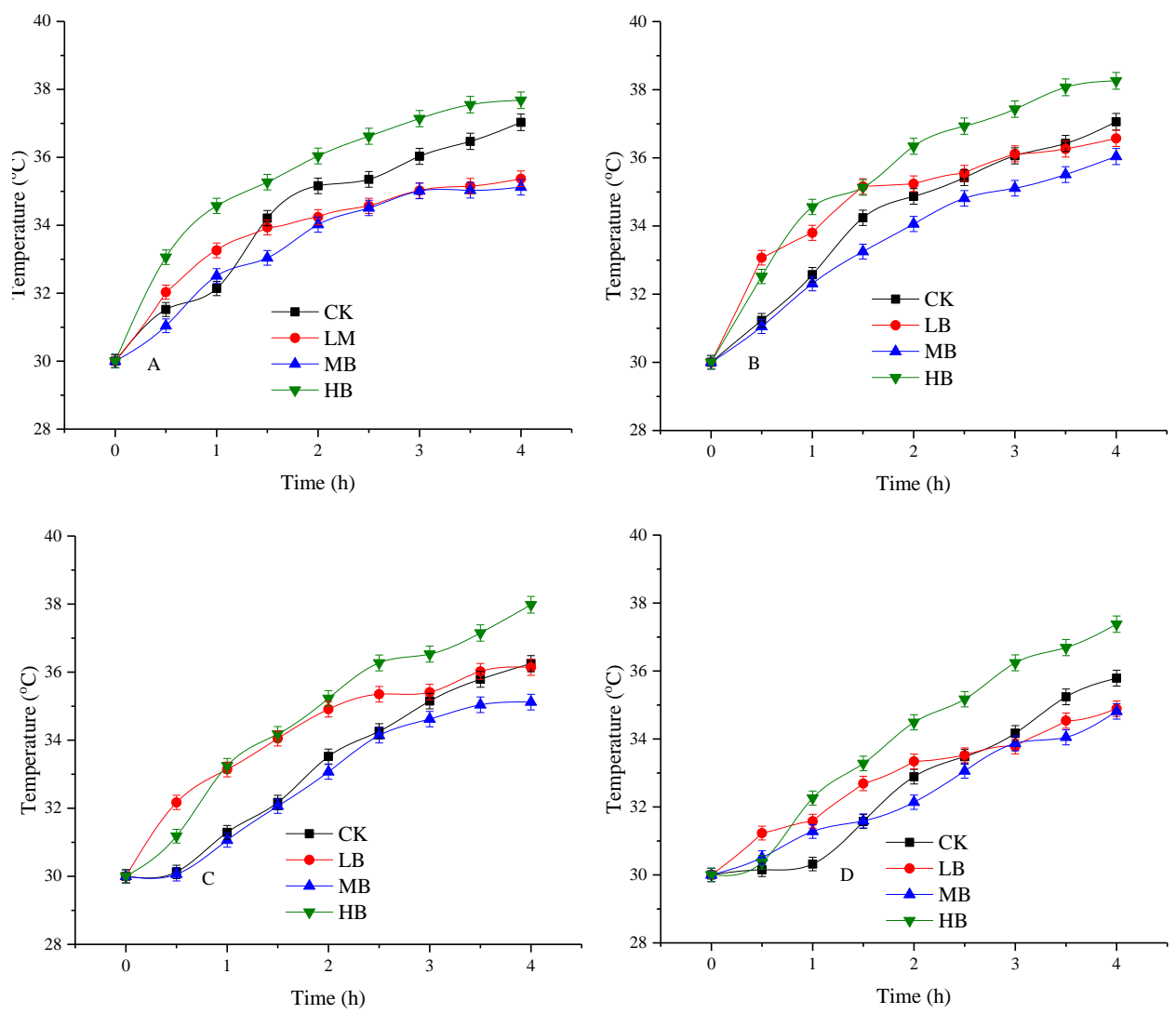

Figure 2. Effect of different wheat straw biochar application rates on soil temperature at different depths: A-5 cm, B-10 cm, C-15 cm, and D-20 cm (with initial soil moisture $20 \%$, air temperature $50{ }^{\circ} \mathrm{C}$ and air humidity $40 \%$ ). CK, control; LB, low biochar; $\mathrm{MB}$, medium biochar; $\mathrm{HB}$, high biochar.

\subsubsection{Effect of WSB Application on Soil Temperature Variations at 20\% Soil Moisture Contents}

As shown in Figure 2, significant variation in soil temperature occurred with increasing rate of WSB application at $20 \%$ soil moisture contents. Soil temperature recorded at the 5 -cm depth for CK, LB, $\mathrm{MB}$, and $\mathrm{HB}$ treatments were $37.03,35.37,35.12$, and $37.68^{\circ} \mathrm{C}$, respectively, at the end of the experiment (4th h) (Figure 2A). As the depth increased up to $10 \mathrm{~cm}$, the temperature also increased as compared to the 5-cm depth at the same time. The temperature of LB and MB treatment were on average higher by 0.49 and $1.02{ }^{\circ} \mathrm{C}$, respectively, compared to CK $20 \%$ at the 5 -cm depth (Figure 2B). With a further increase of depth $(15 \mathrm{~cm}$ and $20 \mathrm{~cm})$, the temperature began to decrease compared to the 10-cm depth. At the $15-\mathrm{cm}$ depth, MB treatment decreased the temperature by $0.93{ }^{\circ} \mathrm{C}$ compared to the $\mathrm{CK} 20 \%$ (Figure 2C). At the 20-cm depth, soil temperature in LB, MB, and $\mathrm{HB}$ treatment was lower by 0.90 , 0.98 , and $1.59^{\circ} \mathrm{C}$, respectively, compared to CK $20 \%$ (Figure 2D). High soil surface and air temperature is known to cause high soil temperature. Our study demonstrates that with increasing the WSB application rate and soil depth, there were significant differences recorded. Particularly at the $15-\mathrm{cm}$ depth the rise in temperature was prominent. The modification of soil temperature by WSB treatment might be due to significant changes in thermal conductivity (Table 1). Numerous reports suggest that higher pyrolysis temperatures increase the crystallinity of biochar while BCs produced from crop residues at lower-medium temperatures possess high CEC and surface functionality and such BCs do not convert lignin into a hydrophobic polycyclic aromatic hydrocarbon and thus BC becomes more hydrophilic. Moreover, the Smooth surface structure can only be obtained for temperature below $400{ }^{\circ} \mathrm{C}$ in the case of crop residues. Herath et al. [33] also suggested that the hydrophobicity of BC is expected to increase with the increase of temperature through the decarboxylation reaction, while poorly carbonized $\mathrm{BC}$ can also contribute to hydrophobicity. Thus, the $\mathrm{BC}$ produced at moderate 
temperatures $\left(300-400{ }^{\circ} \mathrm{C}\right)$, like here in our case, also impacted the soil physical properties. Therefore, the effect of WSB on soil temperature under high soil surface temperature was influenced by soil moisture content, soil depth, WSB application rates, and time of high surface temperature. In this study, MB exhibited best performance of mitigating soil temperature fluctuation at both $10 \%$ and $20 \%$ soil moisture content under high surface temperature.

\section{Conclusions}

In this study, the addition of WSB resulted in the increase of soil temperature from 5- to $10-\mathrm{cm}$ depth and then the decrease from 10 to $20 \mathrm{~cm}$, both under $10 \%$ and $20 \%$ soil moisture contents. WSB addition proved to be a medium for heat exchange between the soil and the atmosphere, interfering with the bi-directional heat movement. Addition of WSB at high dosage effectively improved the soil accumulated temperature especially apparent at the 10-15 cm soil layer. Under 10\% soil moisture content, the soil temperature was significantly raised by LB and HB treatments, compared to the control throughout the $0-20 \mathrm{~cm}$ soil profile. On the contrary, the MB treatment effectively decreased the soil temperature, compared to CK $20 \%$, under high air temperature $\left(50{ }^{\circ} \mathrm{C}\right)$ and low air moisture $(40 \%)$. Therefore, our results suggest that the application of WSB at a medium dose can mitigate soil temperature fluctuation under high surface temperatures in arid and semiarid coal mining areas of China. However, the correlations between soil water content, bulk density, and temperature need to be explored further in field scale studies.

Author Contributions: Conceptualization, J.X.; methodology, J.X.; software, R.Y.; validation, J.X., F.Z. and R.Y.; formal analysis, J.X.; investigation, R.Y.; resources, J.Z.; data curation, J.X.; writing-original draft preparation, J.X. and E.I.; writing-review and editing, J.X. and M.I.S.; visualization, J.X.; supervision, J.X.; project administration, J.Z.; funding acquisition, J.Z. All authors have read and agreed to the published version of the manuscript.

Funding: This study was supported by the Fundamental Research Funds for the China Central Universities (Grant No. 2017XKZD13).

Conflicts of Interest: The authors declare no conflict of interest.

\section{References}

1. Khoshkhoo, Y.; Jansson, P.E.; Irannejad, P.; Khalili, A.; Rahimi, H. Calibration of an energy balance model to simulate wintertime soil temperature, soil frost depth, and snow depth for 14 year period in a highland area of Iran. Cold Reg. Sci. Technol. 2015, 119, 47-60. [CrossRef]

2. Mosier, A.R. Soil processes and global change. Biol. Fert. Soils 1998, 27, 221-229. [CrossRef]

3. Abu-Hamdeh, N.H.; Reeder, R.C. Soil thermal conductivity: Effects of density, moisture, salt concentration, and organic matter. Soil Sci. Soc. Am. J. 2000, 64, 1285-1290. [CrossRef]

4. Lei, S.; Bian, Z.; Daniels, J.L.; He, X. Spatio-temporal variation of vegetation in arid and vulnerable coal mining region. Min. Sci. Technol. 2000, 20, 485-490. [CrossRef]

5. Qian, M.G. Technological system and green mining concept. Coal Sci. Technol. Mag. 2003, 4, 1-3.

6. Tripathi, N.; Singh, R.S.; Singh, J.S. Impact of post-mining subsidence on nitrogen transformation in southern tropical dry deciduous forest, China. Environ. Res. 2009, 109, 258-266. [CrossRef]

7. O'Brien, P.L.; Hatfield, J.L. Extreme soil surface temperatures reflect need to rethink agronomic management. Agric. Environ. Lett. 2020, 5, 1-5. [CrossRef]

8. Liu, B.; Henderson, M.; Wang, L.; Shen, X.; Zhou, D.; Chen, X. Climatology and trends of air and soil surface temperatures in the temperate steppe region of North China. Int. J. Clim. 2017, 37, 1199-1209. [CrossRef]

9. Xu, X.; Luo, Y.; Zhou, J. Carbon quality and the temperature sensitivity of soil organic carbon decomposition in tallgrass prairie. Soil Biol. Biochem. 2012, 50, 142-148. [CrossRef]

10. Xu, Q.; Huang, B. Growth and Physiological Responses of Creeping Bentgrass to Changes in Air and Soil Temperatures. Crop Sci. 2000, 40, 1363-1368. [CrossRef]

11. Aidoo, M.K.; Bdolach, E.; Fait, A.; Lazarovitch, N.; Rachmilevich, S. Growth and Physiological Responses of Creeping Bentgrass to Changes in Air and Soil Temperatures. Plant Physiol. Bioch. 2016, 106, $73-81$. [CrossRef] [PubMed] 
12. Lehmann, J.; Joseph, S. Biochar for Environmental Management: An introduction. In Biochar for Environmental Management: Science and Technology; Earthscan: London, UK, 2009; pp. 1-12.

13. Montanarella, L.; Lugato, E. The Application of Biochar in the EU: Challenges and Opportunities. Agronomy 2013, 3, 462-473. [CrossRef]

14. Razzaghi, F.; Obour, P.B.; Arthur, E. Does biochar improve soil water retention? A systematic review and meta-analysis. Geoderma 2019, 361, 114055. [CrossRef]

15. Abel, S.; Peters, A.; Trinks, S.; Schonsky, H.; Facklam, M.; Wessolek, G. Impact of biochar and hydrochar addition on water retention and water repellency of sandy soil. Geoderma 2013, 202-203, 183-191. [CrossRef]

16. Ding, Y.; Gao, X.; Qu, Z.; Jia, Y.; Hu, M.; Li, C. Effects of biochar application and irrigation methods on soil temperature in farmland. Water 2019, 11, 499. [CrossRef]

17. Cheng, Z.L.; Lam, K.S.; Chan, L.Y.; Wang, T.; Cheng, K.K. Chemical characteristics of aerosols at coastal station in Hong Kong. I. Seasonal variation of major ions, halogens and mineral dusts between 1995 and 1996. Atmos. Environ. 2000, 34, 2771-2783. [CrossRef]

18. Clare, A.; Barnes, A.; McDonagh, J.; Shackley, S. From rhetoric to reality: Farmer perspectives on the economic potential of biochar in China. Int. J. Agr. Sustain. 2014, 12, 440-458. [CrossRef]

19. Cook, R.J.; Haglund, W.A. Wheat yield depression associated with conservation tillage caused by root pathogens in the soil not phytotoxins from the straw. Soil Biol. Biochem. 1991, 23, 1125-1132. [CrossRef]

20. Gevaert, A.I.; Miralles, D.G.; de Jeu, R.A.; Schellekens, J.; Dolman, A.J. Soil moisture-temperature coupling in a set of land surface models. J. Geophys. Res. Atmos. 2018, 123, 1481-1498. [CrossRef]

21. Lone, A.H.; Najar, G.R.; Ganie, M.A.; Sofi, J.A.; Ali, T. Biochar for sustainable soil health: A review of prospects and concerns. Pedosphere 2015, 25, 639-653. [CrossRef]

22. Zhao, J.; Ren, T.; Zhang, Q.; Du, Z.; Wang, Y. Effects of biochar amendment on soil thermal properties in the North China Plain. Soil Sci. Soc. Amn. J. 2016, 80, 1157-1166. [CrossRef]

23. Liu, Y.; Yang, S.; Lu, H.; Wang, Y. Effects of biochar on spatial and temporal changes in soil temperature in cold waterlogged rice paddies. Soil Tillage Res. 2018, 181, 102-109. [CrossRef]

24. Li, Q.; Wang, M.; Fu, Q.; Li, T.; Liu, D.; Hou, R.; Li, H.; Cui, S.; Ji, Y. Short-term influence of biochar on soil temperature, liquid moisture content and soybean growth in a seasonal frozen soil area. J. Environ. Manag. 2020, 266, 110609. [CrossRef] [PubMed]

25. Yan, Q.; Dong, F.; Li, J.; Duan, Z.; Yang, F.; Li, X.; Lu, J.; Li, F. Effects of maize straw-derived biochar application on soil temperature, water conditions and growth of winter wheat. Eur. J. Soil Sci. 2019, 70, 1280-1289. [CrossRef]

26. Uno, U.E.; Emetere, M.E.; Adelabu, J.S. Parametric investigation of soil susceptibility to compaction using temperature deviation curves. Sci. J. Civ. Eng. Arch. 2012, 2012, 1-6.

27. Zhang, Q.; Wang, Y.; Wu, Y.; Wang, X.; Du, Z.; Liu, X.; Song, J. Effects of biochar amendment on soil thermal conductivity, reflectance, and temperature. Soil Sci. Soc. Am. J. 2013, 77, 1478-1487. [CrossRef]

28. Xiao, Q.; Zhu, L.X.; Shen, Y.F.; Li, S.Q. Sensitivity of soil water retention and availability to biochar addition in rainfed semi-arid farmland during a three-year field experiment. Field Crops Res. 2016, 196, $284-293$. [CrossRef]

29. Usowicz, B.; Lipiec, J.; Lukowski, M.; Marczewski, W.; Usowicz, J. The effect of biochar application on thermal properties and albedo of loess soil under grassland and fallow. Soil Tillage Res. 2016, 164, 45-51. [CrossRef]

30. Wu, G.L.; Zhang, M.Q.; Liu, Y.; López-Vicente, M. Litter cover promotes biocrust decomposition and surface soil functions in sandy ecosystem. Geoderma 2020, 374, 114429. [CrossRef]

31. Karimi, A.; Moezzi, A.; Chorom, M.; Enayatizamir, N. Application of biochar changed the status of nutrients and biological activity in a calcareous soil. J. Soil Sci. Plant. Nutr. 2020, 20, 450-459. [CrossRef]

32. Oguntunde, P.G.; Abiodun, B.J.; Ajayi, A.E.; van de Giesen, N. Effects of charcoal production on soil physical properties in Ghana. J. Plant Nutr. Soil Sci. 2008, 171, 591-596. [CrossRef]

33. Herath, H.M.S.K.; Camps-Arbestain, M.; Hedley, M. Effect of biochar on soil physical properties in two contrasting soils: An Alfisol and an Andisol. Geoderma 2013, 209, 188-197. [CrossRef]

(C) 2020 by the authors. Licensee MDPI, Basel, Switzerland. This article is an open access article distributed under the terms and conditions of the Creative Commons Attribution (CC BY) license (http://creativecommons.org/licenses/by/4.0/). 